\title{
Peran dan Mutu Pelaksanaan Pembelajaran oleh Guru di Satuan Pendidikan Tingkat Atas
}

\author{
Zulhafizh \\ Program Studi Pendidikan Bahasa dan Sastra Indonesia, FKIP, Universitasa Riau \\ Corresponding Author. Email: zulhafizh@lecturer.unri.ac.id
}

\begin{abstract}
The purpose of research to analyze the implementation of the role and the quality of learning carried out by teachers in upper-level education units. This research uses descriptive correlation method. The research sample consisted of 142 people who were spread across several upper level education units in Siak Regency, Riau Province. The instrument used for data collection was a Likert scale questionnaire. The analysis technique uses descriptive statistics, Product Moment correlation, normality, and anova. The results showed that all the actions taken had a significant role, namely reaching $47.8 \%$, while $52.3 \%$ was determined by other factors. All activities carried out have an influence on the form of learning. The implementation of learning carried out in the upper level education unit has a very high quality standard. The teachers have taken appropriate actions to achieve learning objectives. The ability and skills of teachers in carrying out their duties are a means of realizing productive learning.
\end{abstract}

\begin{abstract}
Abstrak: Tujuan penelitian ini adalah untuk menganalisis pelaksanaan peran dan mutu pembelajaran yang dilakukan pada guru di satuan pendidikan tingkat atas. Penelitian ini menggunakan metode korelasi deskriptif. Sampel penelitian berjumlah 142 orang yang tersebar di beberapa satuan pendidikan tingkat atas di Kabupaten Siak Provinsi Riau. Instrumen yang digunakan untuk pengumpulan data berupa angket skala Likert. Teknik analisis menggunakan statistik deskriptif, korelasi Product Moment, normalitas, dan anova. Hasil penelitian menunjukkan bahwa seluruh tindakan yang dilakukan memberikan peranan yang signifikan, yaitu mencapai 47,8\%, sedangkan 52,3\% ditentukan oleh faktor lainya. Semua aktivitas yang dilakukan memberikan pengaruh terhadap wujud pembelajaran. Pelaksanaan pembelajaran yang dilakukan di satuan pendidikan tingkat atas berstandar mutu sangat tinggi. Para guru telah melakukan tindakan yang semestinya untuk mencapai tujuan pembelajaran. Kemampuan dan keterampilan guru dalam melaksanakan tugasnya menjadi sarana dalam mewujudkan pembelajaran yang produktif.
\end{abstract}

Article History

Received: 05-01-2021

Revised: 20-02-2021

Accepted: 21-04-2021

Published: 07-06-2021

Key Words:

Role, Quality,

Learning, Teacher,

Senior High School.

\section{Sejarah Artikel}

Diterima: 05-01-2021

Direvisi: 20-02-2021

Disetujui: 21-04-2021

Diterbitkan: 07-06-2021

\section{Kata Kunci:}

Peran, Mutu,

Pembelajaran, Guru,

Pendidikan Tingkat Atas.

How to Cite: Zulhafizh, Z. (2021). Peran dan Mutu Pelaksanaan Pembelajaran oleh Guru di Satuan Pendidikan Tingkat Atas. Jurnal Kependidikan: Jurnal Hasil Penelitian dan Kajian Kepustakaan di Bidang Pendidikan, Pengajaran dan Pembelajaran, 7(2), 328-339. doi:https://doi.org/10.33394/jk.v7i2.3344

d. https://doi.org/10.33394/jk.v7i2.3344

This is an open-access article under the CC-BY-SA License.

\section{Pendahuluan}

Satuan pendidikan atau lebih dikenal dengan sekolah merupakan lembaga formal yang memfasilitasi kegiatan belajar mengajar. Di lembaga ini terjadi interaksi antara guru dan siswa dalam berbagi informasi dan pengalaman. Proses interaksi dapat terjadi dalam situasi pembelajaran maupun di luar aktivitas pembelajaran (Mustafa el al, 2020). Aktivitas tersebut dilaksanakan di satuan pendidikan Kabupaten Siak, Provinsi Riau. Kabupaten ini merupakan salah satu kabupaten di Provinsi Riau yang memiliki guru berkompetensi profesional berkategori tinggi (Febrialismanto, 2017). Keadaan ini menguatkan kedudukan pendidikan di kabupaten tersebut semakin baik pula. Dalam hal ini, kedudukan guru merupakan bagian penting dalam penyelenggaraan pembelajaran. Guru tidak hanya memiliki tugas mengajar, 
juga mendidik, membimbing, menilai, mengevaluasi, dan sebagainya (Mustafa \& Zulhafizh, 2017; Zulfiati, 2014).

Tugas-tugas guru dapat terlaksana secara jelas saat pelaksanaan pembelajaran. Diantara banyak tugas guru adalah mengajar, yaitu mentransformasi informasi dan pengalaman sehingga siswa memiliki wawasan dan pengalaman hidup. Untuk mewujudkan hal tersebut, seorang guru harus mempersiapkan diri secara pedagogis dan profesional (Clouder, 2005; Bamber \& Tett, 2000). Artinya, pembelajaran tidak bisa dilakukan serta merta tanpa ada bekal atau persiapan yang memadai. Aktivitas pembelajaran ini erat kaitannya dengan hajat pendidikan yang tertuang dalam kurikulum pembelajaran. Guru harus paham terhadap tuntutan kurikulum agar bisa mengimplementasikan dalam kegiatan pembelajaran. Jika guru tidak mengerti dengan tuntutan kurikulum, maka sulit mengimplementasikan kepada siswa (Zulhafizh, 2020; Harris el al 2009).

Pelaksanaan pembelajaran bukan suatu yang sederhana, tetapi aktivitas yang sangat kompleks. Untuk sukses dalam mentransformasi informasi dan pengalaman, guru harus memiliki banyak strategi dan pengalaman (Mustafa et al, 2020; Nissa, 2018). Secara kualifikasi akademik, guru mengajar sesuai dengan keahliannya agar bisa mengelola informasi yang diharapkan dalam kurikulum pembelajaran (Mustafa \& Zulhafizh, 2019; 2017). Maka, seseorang yang mengajar bukan karena keahlian dan kualifikasinya dapat mengganggu peran dan mutu pembelajaran yang dilakukannya. Artinya, menjadi guru tidak bisa berlandaskan cinta dengan profesi guru tetapi juga harus mengerti, menguasai, dan mampu mengimplementasi metodologi pembelajaran. Disinilah letak substansi profesi guru yang harus dilakukan untuk mentransformasi informasi dan pengalaman melalui kegiatan pembelajaran.

Dalam metodologi pembelajaran, sekurang-kurangnya guru harus paham dan mengerti apa saja yang harus dikuasai dalam pelaksanaan pembelajaran (Mustafa el al, 2020; 2019; Rusdin, 2018). Beberapa hal yang harus dipahami secara teknis dan praktis yaitu membuka pelajaran dengan metode yang sesuai, menyajikan materi pelajaran secara sistematis dan representatif, menerapkan metode dan prosedur pembelajaran yang telah ditentukan, mengatur kegiatan siswa di kelas dengan prinsip keseimbangan dan kenyamanan menggunakan media pembelajaran, peralatan praktikum (dan bahan) yang telah ditentukan, menggunakan sumber belajar yang telah dipilih (berupa buku, modul, program komputer dan sejenisnya), memotivasi siswa dengan berbagai cara yang positif, melakukan interaksi dengan siswa menggunakan bahasa yang komunikatif, memberikan pertanyaan dan umpan balik untuk mengetahui dan memperkuat penerimaan siswa dalam proses pembelajaran, menyimpulkan pembelajaran, dan menggunakan waktu secara efektif dan efisien (Asmani, 2009; UUGD, 2005).

Kemampuan dan kemapanan guru dalam mengimplementasikan indikator yang diungkapkan Asmani (2009) dan UUGD (2005) dapat menjadi acuan dalam mensukseskan pembelajaran. Ketidakmampuan dalam guru dalam mengimpementasikan indikator tersebut tentu dapat mengganggu keseimbangan pembelajaran. Syamsinar dan Jabu (2015); Mupa Chinooneka (2015); Rubio (2010) dalam kontek ini profesionalitas seorang guru dalam menjalankan aktivitas pembelajaran tidak bisa asal tetapi ia harus mengerti teknis pelaksanaan dan kebutuhan. Menjadi profesional merupakan tuntutan agar pembelajaran yang dilakukan seorang berjalan secara efektif dan jelas capaian tujuan pembelajaran (Killen 2006; Stronge et al, 2004; Gibbs, 2002). Penelitian Shepherd (2013); Derakhshan dan Shirmohammadli (2010) kemampuan dan keterampilan guru secara teknis dan praktis dalam pelaksanaan pembelajaran memberikan dampak kualitas pembelajaran dan capaiannya. Hal ini penting dipahami guru saat menjalankan tugas pembelajarannya. 
Dalam kontek pedagogis dan profesional guru, pemahaman dan kemampuan guru dalam menyelenggarakan pembelajaran merupakan suatu yang spesial untuk siswanya (Zulhafizh, 2020; Ganbarzehi, 2014). Setiap siswa yang belajar mengharapkan adanya pengalaman dan informasi yang ia dapatkan dari kegiatan belajar mengajar. Seluruh rangkaian aktivitas yang didesain guru bagian penting yang tidak terpisahkan dari pengalaman yang akan didapat oleh siswa. Nassaji (2012) dan Lightbown (2000) mengingatkan bahwa guru harus tahu apa saja yang dilakukan dan tidak perlu dilakukan. Sebab, kesalahan tindakan dapat memberikan dampak atau efek buruk dalam pembelajaran. Dampak buruk ini dapat diminalisasi dengan membekali diri keterampilan pedagogis dan profesional. Dangara (2016); Adebayo (2001) menambahkan pengorganisasian adminstrasi juga penting dilakukan sebagai dokumentasi evaluasi pembelajaran. Cara ini sebagai bahan dan dasar tindakan perenungan terhadap kegiatan pembelajaran yang telah dilakukan.

Berdasarkan paparan tersebut, maka penelitian ini bertujuan untuk menganalisis peran dan mutu pelaksanaan pembelajaran oleh guru di satuan pendidikan tingkat atas. Hasilnya dapat menjadi bahan pertimbangan bagi penyelengara pendidikan dalam mewujudkan pembelajaran yang bermutu dan berkualitas, khususnya bagi guru. Guru bisa memaksimalkan kinerja mengejar melalui indikator pelaksanaan pembelajaran sehingga terwujud kinerja dan capaian pembelajaran yang ditargetkan.

\section{Metode Penelitian}

Penelitian ini dilakukan dengan metode deskriptif. Dasar pendeskripsian bertolok pada instrumen yang digunakan untuk pengumpulan data yaitu berupa angket. Intrumen ini terdiri dari sembilan pokok penting yang berkaitan dengan penyusunan rencana pembelajaran yang dilakukan para guru-guru di satuan pendidikan tingkat atas Kabupaten Siak Provinsi Riau. Instrumen diadaptasi dari Asmani (2009) dan UUGD (2005) yang berhubungan dengan tata pengelolaan kelas. Instrumen dibuat dengan Skala Likert yang terdiri dari lima opsi jawaban atau tanggapan. Instrumen atau angket sebarkan kepada para guru secara daring dengan memanfaatkan google form.

Sampel penelitian adalah para guru yang mengajar di satuan pendidikan tingkat atas di kabupaten Siak, yaitu berjumlah 142 orang yang tersebar di SMAN 1 Siak, SMAN 2 Siak, SMAN 1 Bungaraya, SMAN 1 Sei Apit, dan SMAN 1 Tualang. Sampel dilakukan secara random sampling sesuai dengan kesiapan responden mengisi dan mengirimkan tanggapannya. Analisis data dilakukan dengan mensubsitusikan hasil responden melalui statistik deskriptif. Selanjutnya, untuk melihat relevansi dan kaitan instrumen terhadap pelaksanaan pembelajaran menggunakan metode korelasi Product Moment, normalitas dengan chi kuadrat, kontribusi indikator dalam mewujudkan keberhasilan pelaksaan pembelajarn melalui Anova.

\section{Hasil Penelitian dan Pembahasan Deskripsi Data}

Hasil analisis aspek melaksanakan pembelajaran, baik yang berkaitan dengan metode, materi, media, movitasi, proses interaksi dan sebagainya pada responden dapat diamati melalui mean dan standar deviasi yang berkaitan dengan loyalitas guru Sekolah Menengah Atas dalam meningkatkan mutu pembelajaran melalui pengelolaan kelas di Kabupaten Siak Provinsi Riau, yaitu: 
Tabel 1. Interpretasi Pengelolaan Kelas Aspek Melaksanakan Pembelajaran

\begin{tabular}{|c|c|c|c|c|}
\hline No. & Indikator & Mean & SD & Kategori \\
\hline 1 & $\begin{array}{l}\text { Membuka pelajaran dengan } \\
\text { metode yang sesuai }\end{array}$ & 4,360 & 0,728 & Sangat tinggi \\
\hline 2 & $\begin{array}{l}\text { Menyajikan materi pelajaran } \\
\text { secara sistematis dan } \\
\text { representatif }\end{array}$ & 4,270 & 0,800 & Sangat tinggi \\
\hline 3 & $\begin{array}{l}\text { Menerapkan metode dan } \\
\text { prosedur pembelajaran yang } \\
\text { telah ditentukan }\end{array}$ & 4,150 & 0,727 & Sangat tinggi \\
\hline 4 & $\begin{array}{l}\text { Mengatur kegiatan siswa di kelas } \\
\text { dengan prinsip keseimbangan } \\
\text { dan kenyamanan }\end{array}$ & 4,410 & 0,686 & Sangat tinggi \\
\hline 5 & $\begin{array}{l}\text { Menggunakan media } \\
\text { pembelajaran, peralatan } \\
\text { praktikum (dan bahan) yang } \\
\text { telah ditentukan }\end{array}$ & 3,900 & 0,828 & Tinggi \\
\hline 6 & $\begin{array}{l}\text { Menggunakan sumber belajar } \\
\text { yang telah dipilih (berupa buku, } \\
\text { modul, program komputer dan } \\
\text { sejenisnya) }\end{array}$ & 4,390 & 0,714 & Sangat tinggi \\
\hline 7 & $\begin{array}{l}\text { Memotivasi siswa dengan } \\
\text { berbagai cara yang positif }\end{array}$ & 4,600 & 0,664 & Sangat tinggi \\
\hline 8 & $\begin{array}{l}\text { Melakukan interaksi dengan } \\
\text { siswa menggunakan bahasa yang } \\
\text { komunikatif }\end{array}$ & 4,580 & 0,676 & Sangat tinggi \\
\hline 9 & $\begin{array}{l}\text { Memberikan pertanyaan dan } \\
\text { umpan balik untuk mengetahui } \\
\text { dan memperkuat penerimaan } \\
\text { siswa dalam proses pembelajaran }\end{array}$ & 4,470 & 0,649 & Sangat tinggi \\
\hline 10 & Menyimpulkan pembelajaran & 4,370 & 0,739 & Sangat tinggi \\
\hline 11 & $\begin{array}{l}\text { Menggunakan waktu secara } \\
\text { efektif dan efisien. }\end{array}$ & 4,370 & 0,701 & Sangat tinggi \\
\hline & Mean & 4,352 & 0,719 & Sangat tinggi \\
\hline
\end{tabular}

Data tabel 1 diatas menggambarkan ada sebelas pernyataan yang mengarah pada aspek melaksanakan pembelajaran. Adapun sebelas pernyataan tersebut, yaitu: pertama, membuka pelajaran dengan metode yang sesuai berkategori sangat tinggi dengan mean 4,360 pada standar deviasi 0,728 ; kedua menyajikan materi pelajaran secara sistematis dan representatif berkategori sangat tinggi dengan mean 4,270 pada standar deviasi 0,800; ketiga, menerapkan metode dan prosedur pembelajaran yang telah ditentukan berkategori sangat tinggi dengan mean 4,150 pada standar deviasi 0,727, keempat, mengatur kegiatan siswa di kelas dengan prinsip keseimbangan dan kenyamanan berkategori sangat tinggi dengan mean 4,410 pada standar deviasi 0,686 .

Kelima, menggunakan media pembelajaran, peralatan praktikum (dan bahan) yang telah ditentukan berkategori tinggi dengan mean 3,900 pada standar deviasi 0,828; keenam, menggunakan sumber belajar yang telah dipilih (berupa buku, modul, program komputer dan sejenisnya) berkategori sangat tinggi dengan mean 4,390 pada standar deviasi 0,714; ketujuh, 
memotivasi siswa dengan berbagai cara yang positif berkategori sangat tinggi dengan mean 4,600 pada standar deviasi 0,664; kedelapan, melakukan interaksi dengan siswa menggunakan bahasa yang komunikatif berkategori sangat tinggi dengan mean 4,580 pada standar deviasi 0,676.

Kesembilan, memberikan pertanyaan dan umpan balik untuk mengetahui dan memperkuat penerimaan siswa dalam proses pembelajaran berkategori sangat tinggi dengan mean 4,470 pada standar deviasi 0,649; kesepuluh, menyimpulkan pembelajaran berkategori sangat tinggi dengan mean 4,370 pada standar deviasi 0,739; dan kesebelas, menggunakan waktu secara efektif dan efisien berkategori sangat tinggi dengan mean 4,370 pada standar deviasi 0,701. Data-data tersebut memberikan penjelasan bahwa secara keseluruhan untuk aspek melaksanakan pembelajaran pada loyalitas guru Sekolah Menengah Atas dalam meningkatkan mutu pembelajaran melalui pengelolaan kelas di Kabupaten Siak Provinsi Riau menunjukkan standar sangat tinggi dengan mean 4,352 pada standar deviasi 0,719.

Tabel 2. Korelasi Indikator Pelaksanaan Pembelajaran

\begin{tabular}{|c|c|c|c|c|c|}
\hline No. & Indikator & $\begin{array}{c}\text { Korelasi } \\
(\mathbf{0 , 0 5})\end{array}$ & Alfa & $\mathbf{F}$ & Kategori \\
\hline 1 & $\begin{array}{l}\text { Membuka pelajaran dengan } \\
\text { metode yang sesuai }\end{array}$ & $0,756^{* *}$ & 0,773 & 0,000 & Sangat kuat \\
\hline 2 & $\begin{array}{l}\text { Menyajikan materi pelajaran } \\
\text { secara sistematis dan } \\
\text { representatif }\end{array}$ & $0,803 * *$ & 0,773 & 0,000 & Sangat kuat \\
\hline 3 & $\begin{array}{l}\text { Menerapkan metode dan } \\
\text { prosedur pembelajaran yang } \\
\text { telah ditentukan }\end{array}$ & $0,733 * *$ & 0,773 & 0,000 & Kuat \\
\hline 4 & $\begin{array}{l}\text { Mengatur kegiatan siswa di } \\
\text { kelas dengan prinsip } \\
\text { keseimbangan dan kenyamanan }\end{array}$ & $0,699 * *$ & 0,773 & 0,000 & Kuat \\
\hline 5 & $\begin{array}{l}\text { Menggunakan media } \\
\text { pembelajaran, peralatan } \\
\text { praktikum (dan bahan) yang } \\
\text { telah ditentukan }\end{array}$ & $0,618 * *$ & 0,773 & 0,000 & Kuat \\
\hline 6 & $\begin{array}{l}\text { Menggunakan sumber belajar } \\
\text { yang telah dipilih (berupa buku, } \\
\text { modul, program komputer dan } \\
\text { sejenisnya) }\end{array}$ & $0,748 * *$ & 0,773 & 0,000 & Kuat \\
\hline 7 & $\begin{array}{l}\text { Memotivasi siswa dengan } \\
\text { berbagai cara yang positif }\end{array}$ & $0,773 * *$ & 0,773 & 0,000 & Sangat kuat \\
\hline 8 & $\begin{array}{l}\text { Melakukan interaksi dengan } \\
\text { siswa menggunakan bahasa } \\
\text { yang komunikatif }\end{array}$ & $0,802 * *$ & 0,773 & 0,000 & Sangat kuat \\
\hline 9 & $\begin{array}{l}\text { Memberikan pertanyaan dan } \\
\text { umpan balik untuk mengetahui } \\
\text { dan memperkuat penerimaan } \\
\text { siswa dalam proses } \\
\text { pembelajaran }\end{array}$ & $0,742 * *$ & 0,773 & 0,000 & Kuat \\
\hline 10 & Menyimpulkan pembelajaran & $0,725 * *$ & 0,773 & 0,000 & Kuat \\
\hline 11 & $\begin{array}{l}\text { Menggunakan waktu secara } \\
\text { efektif dan efisien. }\end{array}$ & $0,823 * *$ & 0,773 & 0,000 & Sangat kuat \\
\hline
\end{tabular}




\begin{tabular}{cccccc}
\hline No. & Indikator & $\begin{array}{c}\text { Korelasi } \\
(\mathbf{0 , 0 5})\end{array}$ & Alfa & F & Kategori \\
\hline Mean & $0,747^{* *}$ & 0,773 & 0,000 & Kuat \\
\hline
\end{tabular}

Pada tabel 2 ini dapat diamati bahwa seluruh indikator pengamatan berkorelasi terhadap kegiatan pelaksanaan pembelajaran. Berdasarkan hasil subsitusi tabel korelasi memperlihatkan seluruh data berkorelasi kuat. Hal ini tampak pada kode bintang. Sarwono (2006) tanda bintang dua menunjukkan adanya korelasi terhadap variabel secara positif maupun negatif. Selanjutnya, untuk memastikan data, maka dilakukan uji normalitas dengan uji Chi Kuadrat. Pengujian diperoleh dari perbandingan harga pada taraf signifikansi 0,05.

Tabel 3. Uji Normalitas Data

\begin{tabular}{ccccc}
\hline Kelas & $\mathbf{d k}$ & $\chi_{\text {hitung }}^{2}$ & Sig. & Kerangan \\
\hline Melaksanakan pembelajaran & 1 & 46,930 & 0,000 & Normal \\
\hline
\end{tabular}

Dari tabel 3 di atas diperoleh data uji normalitas yaitu: $0,000<0,05$. Nilai ini menunjukkan bahwa data informasi pelaksanaan pembelajaran berdistribusi normal. Hal ini menegaskan data tersebut dapat dianalisis dan dipertimbangkan dalam mengamati nilai anova.

Tabel 4. Anova Skor Pelaksanaan Pembelajaran

\begin{tabular}{|c|c|c|c|c|c|}
\hline & Indikator Independen & df & SS & $\mathbf{F}$ & Sig. \\
\hline \multirow[t]{11}{*}{$\begin{array}{l}\text { Tipe } \\
\text { Variabel }\end{array}$} & Membuka pelajaran dengan metode & 1 & 46,344 & 11,175 & 0,000 \\
\hline & $\begin{array}{l}\text { Menyajikan materi pelajaran secara } \\
\text { sistematis dan representatif }\end{array}$ & 1 & 61,755 & 14,789 & 0,000 \\
\hline & $\begin{array}{l}\text { Menerapkan metode dan prosedur } \\
\text { pembelajaran yang telah ditentukan }\end{array}$ & 1 & 44,687 & 10,211 & 0,000 \\
\hline & $\begin{array}{l}\text { Mengatur kegiatan siswa di kelas } \\
\text { dengan prinsip keseimbangan dan } \\
\text { kenyamanan }\end{array}$ & 1 & 34,750 & 7,524 & 0,000 \\
\hline & $\begin{array}{l}\text { Menggunakan media pembelajaran, } \\
\text { peralatan praktikum (dan bahan) yang } \\
\text { telah ditentukan }\end{array}$ & 1 & 49,119 & 7,066 & 0,000 \\
\hline & $\begin{array}{l}\text { Menggunakan sumber belajar yang } \\
\text { telah dipilih (berupa buku, modul, } \\
\text { program komputer dan sejenisnya) }\end{array}$ & 1 & 44,237 & 10,921 & 0,000 \\
\hline & $\begin{array}{l}\text { Memotivasi siswa dengan berbagai cara } \\
\text { yang positif }\end{array}$ & 1 & 42,205 & 14,482 & 0,000 \\
\hline & $\begin{array}{l}\text { Melakukan interaksi dengan siswa } \\
\text { menggunakan bahasa yang komunikatif }\end{array}$ & 1 & 46,613 & 17,821 & 0,000 \\
\hline & $\begin{array}{l}\text { Memberikan pertanyaan dan umpan } \\
\text { balik untuk mengetahui dan } \\
\text { memperkuat penerimaan siswa dalam } \\
\text { proses pembelajaran }\end{array}$ & 1 & 34,471 & 9,454 & 0,000 \\
\hline & Menyimpulkan pembelajaran & 1 & 43,793 & 9,023 & 0,000 \\
\hline & $\begin{array}{l}\text { Menggunakan waktu secara efektif dan } \\
\text { efisien. }\end{array}$ & 1 & 50,315 & 18,189 & 0,000 \\
\hline
\end{tabular}

Data tabel 4 memperlihatkan Anova satu arah dalam menentukan perbedaan maupun persamaan pelaksanaan pembelajaran di satuan pendidikan tingkat atas. Seluruh data tidak ada perbedaan dengan signifikansi tidak lebih dari 0,05, yaitu: membuka pelajaran dengan 
metode yang sesuai $(\mathrm{F}=11,175$, sig $=0,000<0,05)$; menyajikan materi pelajaran secara sistematis dan representatif $(F=14,789$, sig $=0,000<0,05)$; menerapkan metode dan prosedur pembelajaran yang telah ditentukan $(\mathrm{F}=10,211$, sig $=0,000<0,05)$; mengatur kegiatan siswa di kelas dengan prinsip keseimbangan dan kenyamanan $(F=7,524$, sig $=$ $0,000<0,05$ ); menggunakan media pembelajaran, peralatan praktikum (dan bahan) yang telah ditentukan $(\mathrm{F}=7,066$, sig $=0,000<0,05)$; menggunakan sumber belajar yang telah dipilih (berupa buku, modul, program komputer dan sejenisnya) $(\mathrm{F}=10,921$, sig $=0,000<$ $0,05)$; memotivasi siswa dengan berbagai cara yang positif $(\mathrm{F}=14,482$, sig $=0,000<0,05)$; melakukan interaksi dengan siswa menggunakan bahasa yang komunikatif $(\mathrm{F}=17,821$, sig $=$ $0,000<0,05)$; memberikan pertanyaan dan umpan balik untuk mengetahui dan memperkuat penerimaan siswa dalam proses pembelajaran $(\mathrm{F}=9,454$, sig $=0,000<0,05)$; menyimpulkan pembelajaran $(F=9,023$, sig $=0,000<0,05)$; dan menggunakan waktu secara efektif dan efisien $(F=18,189$, sig $=0,000<0,05)$. Semua varibel dapat menjadi dasar pengamatan dan digunakan menilai pelaksanaan pembelajaran yang dilakukan guru di satuan pendidikan tingkat atas.

Tabel 5. Harga Peranan Indikator dalam Pelaksanaan Pembelajaran

\begin{tabular}{cccc}
\hline \multirow{2}{*}{ Subjek } & \multicolumn{3}{c}{ Harga } \\
\cline { 2 - 4 } & $\mathbf{r}_{\mathbf{x y}}$ & $\mathbf{r}_{\mathbf{x y}}{ }^{2}$ & Sig. \\
\hline Indikator Indipenden & $0,686^{\mathrm{a}}$ & 0,478 & $0,000^{\mathrm{a}}$
\end{tabular}

Tabel 5 ini memperlihatkan harga peranan variabel pengamatan secara keseluruhan. Hasil luaran diketahui nilai $r$ kuadrat 0,478 . Nilai ini bermakna bahwa seluruh indikator yang dilakukan respinden memberikan peranan atau keberhasilan pelaksanaan pembelajaran sebesar 47,8\% sedangkan 52,3 ditentukan oleh variabel lain seperti perencanaan pembelajaran, penilaian atau pelaksanaan evaluasi, aktivitas refleksi dan sebagainya.

\section{Peran dan Mutu Pembelajaran}

Setiap saat, kegiatan pelaksanaan pembelajaran terus berkembang sesuai dengan tuntutan kebutuhan global. Guru harus berpacu dengan waktu dengan menjadikan pribadi pembelajar. Berbagai metode, teknik, pendekatan, dan model pembelajaran sangat perlu dipelajari. Tidak cukup hanya itu, daya kreativitas guru juga sangat diperlukan untuk melahirkan hal-hal baru. Clarke (2007) menjelaskan bahwa guru harus mampu mengembangkan berbagai teknik, metode, pendekatan, maupun model untuk mewujudkan pembelajaran lebih baik dan kreatif. Apandi dan Raman (2020) menjelaskan bahwa berbagai tawaran dalam pembelajaran dapat diwujudkan sehingga guru dapat memberikan hal-hal positif untuk kemajuan dan kesuksesan siswa. Yew dan Jambulingam (2017) mengungkapkan bahwa kreativitas strategi pembelajaran sebagai tindakan yang dapat memacu dan meningkatkan kualitas belajar mengajar. Temuan penelitian menunjukkan bahwa kemampuan penggunakan teknik, metode, pendekatan, dan penerapan model yang dipilih guru berada pada strandar mutu sangat tinggi.

Selain kemampuan mengkreasi teknik, metode, pendekatan, dan model pembelajaran, guru juga harus memiliki pengetahun untuk mendukung kegiatan pembelajaran (Zulhafizh \& Permatasari, 2020). Tidak setiap saat materi yang akan diberikan kepada siswa didukung dengan sumber belajar. Maka, guru bisa memfasilitasi kegiatan pembelajaran melalui wawasan yang dimiliki. Mustafa dan Zulhafizh (2019); Govindasamy (2001) menjelaskan bahwa guru harus meng-upgrade dan mengembangkan berbagai informasi agar memiliki wawasan yang luas. Guru bisa dengan mudah mentransfer informasi walapun sumber belajar tidak ada. Jika kepastian informasi terkendala, maka usaha capaian pembelajaran juga dapat 
terganggu. Jangan sampai guru tidak mampu menjelaskan harapan siswa dalam belajar. Mustafa dan Zulhafizh (2019) memberikan pandangan bahwa guru diyakini sebagai pemberi informasi dan petunjuk disaat siswa tidak mengetahui dan tidak bisa menyelesaikan masalahnya. Sammons et al (2016) mengungkapkan bahwa guru merupakan sosok yang memberikan inspirasi sehingga menguatkan emosional siswa dalam mengikuti kegiatan pembelajaran.

Seorang guru perlu memikirkan media yang dapat membantu atau memfasilitasi kegiatan pembelajaran (Budiyono, 2020; Mustafa et al, 2019). Media pembelajaran sebagai media yang dapat mempermudah guru untuk menghadirkan informasi secara nyata. Hal yang tidak kalah penting adalah mendorong efektivitas capaian pembelajaran (Mustafa et al, 2019). Misalnya, ketika guru menjelaskan proses pembuahan atau penyerbukan, maka proses itu tidak cukup dengan cerita saja dan lebih efektif jika diinformasikan atau ditayangkan melalui proyektor. Semua proses yang terjadi saat pembuahan atau penyerbukan bisa dicermati dan dipahami siswa. Penggunaan media perlu didukung dengan kemampuan dan keterampilan guru. Mustafa dan Zulhafizh (2019) menjelaskan bahwa penggunaan media yang acuh atau tidak mampu justru dapat merusak suasana pembelajaran. Artinya, guru dapat memilih media pendukung pembelajaran sesuai dengan kapasitas kemampuan dan keterampilannya.

Selain mengelola metode, materi, media, keberhasilan pembelajaran didukung dengan kemampuan mengatur keseimbangan kelas (Asmani, 2009). Keseimbangan ini bisa berkaitan dengan mengatur tata ruang, tempat dan posisi duduk, pencahayaan. Keadaan kelas yang tidak seimbang dengan kebutuhan pembelajaran dapat menghambat aktivitas pembelajaran. Cheawjindakarn (2012) menyatakan keseimbangan kelas sangat membantu kegiatan yang dilakukan, terutama saat melakukan interaksi, umpan balik, maupun tindakan dukungan atau motivasi saat pembelajaran. Tanoto Foundation (2019) menjelaskan proses penempatan kesimbangan ini bisa memakai prinsip MIA (mobilitas, interaksi, dan akses). MIA merupakan suatu cara yang harus diperhatikan guru saat mendesain tempat belajar. Proses mobilisasi, interaksi, dan akses guru dan dan siswa tidak terganggu apalagi terhambat. Proses yang dibentuk memperkuat transformasi informasi dan pengalaman kepada siswa dalam mengikuti pembelajaran.

Selama pelaksanaan pembelajaran berlangsung, kegiatan yang dilakukan guru dibatasi oleh waktu. Setiap mata pelajaran memiliki ragam waktu yang diperlukan. Guru harus bisa memanfaatkan waktu yang ada. Efektivitas waktu pembelajaran sangat penting diperhatikan. Untuk itu, sebelum pembelajaran dilakukan, seorang guru harus membuat perencanaan waktu yang diperlukan untuk setiap aktivitas pembelajaran. Perencanaan waktu sebagai dasar pemetaan ruang gerak guru dan siswa dalam pembelajaran. Dengan perencanaan tersebut, guru dapat mengelola kegiatan untuk mencapai tujuan pembelajaran. Merritt (2016); Foltynek \& Motycka, 2008) menjelaskan bahwa perencanaan waktu merupakan tindakan yang substansi agar guru bisa memilih strategi yang efektif, merancang pelajaran, menyiapkan materi, dan berkolaborasi. Guru yang tidak membuat perencanaan waktu akan mengalami kesulitan dalam memaksimalkan mencapai tujuan pembelajaran (McGoey et al, 2014; Provasnik \& Dorman, 2005).

Di akhir pembelajaran sangat diperlukan simpulan agar siswa dapat memahami secara bersama target dan tujuan pembelajaran. Kegiatan simpulan merupakan tindakan untuk memperkuat dan menyamakan kualitas pemahaman. Setiap siswa mendapat informasi yang sama sehingga memperkuat target capaian pembelajaran. Tanpa simpulan bersama, tentunya dapat menimbulkan keberagaman pemahaman antar siswa. Şişman dan Turan (2004) menyimpulkan kegiatan pembelajaran secara strategi mengembalikan fokus pemahaman 
siswa. Kegiatan ini merupakan aktivitas yang produktif dan menyadarkan siswa terhadap harapan pembelajaran. Akan dan Basar (2013); Cohen (1983) mengingatkan guru harus memastikan saat kegiatan simpulan siswa mengikuti dan memperhatikan secara aktif. Penelitian menunjukkan bahwa keikutsertaan siswa menyimpulkan kegiatan pembelajaran turut mempengaruhi prestasi belajarnya (Reagle, 2006; Kirk \& Jones, 2004; Balc1, 2002; Huitt, 1999).

Pada kontek ini guru dapat memainkan perannya secara maksimal dan terukur agar mutu dan harapan pembelajaran dapat dicapai. Kemampuan dan keterampilan guru dalam melaksanakan tugasnya menjadi sarana dalam mewujudkan pembelajaran yang produktif. Untuk memastikan harapan tersebut, guru harus membekali diri secara maksimal, baik yang bersifat pedagogis maupun pada ranah profesionalitas. Kegagalan guru merupakan jawaban kegagalan siswa dalam belajar. Mustafa dan Zulhafizh (2017) memberikan penegasan bahwa hindari kegagalan pembelajaran melalui memantaskan kemampuan dan keterampilan. Kemampuan dan keterampilan tidak cukup dengan selembar dokumen yang dikeluarkan lembaga formal maupun nonformal, tetapi harus diikuti dengan aktivitas belajar sepanjang hayat sebagai strategi meningkatkan kualitas profesionalisme.

\section{Kesimpulan}

Kesimpulan yang diperoleh dari hasil penelitian ini adalah setiap tindakan yang dilakukan guru saat pembelajaran memiliki peranan yang sangat penting. Semua aktivitas yang dilakukan memberikan pengaruh terhadap wujud pembelajaran. Aktivitas atau pelaksanaan pembelajaran yang dilakukan di satuan pendidikan tingkat atas Kabupaten Siak Provinsi Riau berstandar mutu sangat tinggi. Para guru telah melakukan tindakan yang semestinya untuk mencapai tujuan pembelajaran. Data menunjukkan bahwa seluruh tindakan yang dilakukan telah memberikan peranan yang signifikan, yaitu mencapai 47,8\% sedangkan 52,3\% ditentukan oleh faktor lainya. Capaian ini bisa ditingkat dengan meningkatkan kemampuan pedagogik dan keterampilan profesional guru. Peningkatan tersebut dapat membantu guru dalam menyeimbangi tuntutan global.

\section{Saran}

Berdasarkan hasil penelitian memperlihatkan bahwa peran dan mutu pembelajaran di satuan pendidikan tingkat atas berlangsung dengan baik. Selama guru patuh dan melaksananakn indikator pelaksanaan pembelajaran maka dapat meningkatkan profesionalitas guru tersebut. Untuk itu bagi guru hendaknya meningkatkan kualtias dan kreatifitasnya dalam mendesain pembelajaran sehingga dapat meningkatkan mutu pembelajaran dan juga pendidikan di lingkungan satuan pendidikan tingkat atas. Bagi peneliti lanjutan dapat melakukan evaluasi dan efektivitas pelaksnaaan pembelajaran di satuan pendidikan lainnya dalam berbagai perspektif pengamatan.

\section{Daftar Pustaka}

Adebayo, A. (2001). Principles and Practice of Public Administration in Nigeria. Ibadan: Spectrum Books Ltd.

Akan, D., \& Basar, M. (2013). The Effect of the Classroom Activities on Classroom Management in the Teaching-Learning Process: The Case of Uşak City. Mevlana International Journal of Education, 3(4), 147-165.

Apandi, A. M., \& Raman, A. (2020). Factors Affecting Successful Implementation ofBlended Learning at Higher Education. International Journal of Instruction, Technology, and Social Sciences (IJITSS), 1(1),13-23. 
Asmani, J. M. (2009). 7 Kompetensi Guru Menyenangkan dan Professional. Jogjakarta: Power Books.

Balc1, A. (2002). Effective School-School Development Theories Practices and Research. Ankara: Pegem Publishing.

Bamber, J., \& Tett, L. (2000). Transforming the Learning Experiences of Non-Traditional Students: A Perspective from Higher Education. Studies in continuing education, 22(1), 57-75.

Budiyono, B. (2020). Inovasi Pemanfaatan Teknologi Sebagai Media Pembelajaran di Era Revolusi 4.0. Jurnal Kependidikan: Jurnal Hasil Penelitian dan Kajian Kepustakaan di Bidang Pendidikan, Pengajaran dan Pembelajaran, 6(2), 300-309. doi:https://doi.org/10.33394/jk.v6i2.2475

Cheawjindakarn, B., Suwannatthachote, P., \& Theeraroungchaisri, A. (2013). Critical Success Factors for Online Distance Learning in Higher Education: A Review of the Literature. Creative Education, 3(08), 61-66.

Clarke, A. (2007). The Future of E-Learning. Adults Learning, 18(7), 14-15.

Clouder, L. (2005). Caring as a 'Threshold Concept': Transforming Students in Higher Education Into Health (Care) Professionals. Teaching in higher education, 10(4), 505517.

Cohen, M.(1983). Instructional Management and Social Conditions. In Effective School (School Finance And School improvement Ed: OddenA; Weeb D. L.). Cambridge, Massachusetts: Ballinger Publishing Company.

Dangara, Y. (2016). Educational Resources: An Integral Component for Effective School Administration in Nigeria. Journal of Research in Humanities and Social Sciences, 6(13), 18-39.

Derakhshan, A., \& Shirmohammadli, M. (2015). The Difficulties of Teaching English Language: The Relationship between Research and Teaching. International Journal of linguistics, 7(1), 102-110.

Febrialismanto. (2017). Analisis Kompetensi Profesional Guru PAUD Kabupaten Siak Provinsi Riau. Jurnal PG-PAUD Trunojoyo: Jurnal Pendidikan dan Pembelajaran Anak Usia Dini, 4(2), 103-114.

Foltynek, T., \& Motycka, A. (2008). Time Management in E-Learning. Czech Republic: Faculty of Business and Economics, Department of Informatics, Mendel University.

Ghanbarzehi, F. A. (2014). Language Learning Strategy Use and Its Correlation with EFL Male and. The Iranian EFL Journal, 28, 384-496.

Gibbs, C. J. (2002). Effective Teaching: Exercising Self-Efficacy and Thought Control of Action. Auckland University of Technology, New Zealand, Annual Conference of the British Educational Research Association Exeter England. http://www.leeds.ac.uk/educol/documents/ 00002390.htm

Govindasamy, T. (2001). Successful Implementation of E-Learning: Pedagogical Considerations. The Internet and Higher Education, 4(3-4), 287-299.

Harris, J., Mishra, P., \& Koehler, M. (2009). Teachers' Technological Pedagogical Content Knowledge and Learning Activity Types: Curriculum-Based Technology Integration Reframed. Journal of Research on Technology in Education, 41(4), 393-416.

Huitt, W. (1999). Implementing Effective School Achievement Reform: Four Principles. Paper presented at the Eighth Annual Applied Psychology Conference, Valdosta, GA, Retrieved from http://www.edpsycinteractive.org/papers/school_reform.pdf.

Killen, R. (2006). Effective Teaching Strategies: Lessons from Research and Practice. Australia: Cengage Learning Australia. 
Kirk D. J., Jones T. L. (2004). Effective Schools (Assessment Report). San Antonio: Pearson Education, Inc.

Lightbown, P. M. (2000). Anniversary Article. Classroom SLA Research and Second Language Teaching. Applied linguistics, 21(4), 431-462.

McGoey, K.E., Rispoli, K.M., Venesky, L.G., Schaffner, K.F., McGuirk, L., \& Marshall, S. (2014). A Preliminary Investigation Into Teacher Perceptions of the Barriers To Behavior Intervention Implementation. Journal of Applied School Psychology, 30 (4), 375-390.

Merritt, E. G. (2016). Time for Teacher Learning, Planning Critical for School Reform. Phi Delta Kappan, 98(4), 31-36.

Mupa, P., \& Chinooneka, T. I. (2015). Factors Contributing to Ineffective Teaching and Learning in Primary Schools: Why Are Schools in Decadence?. Journal of Education and Practice, 6(19), 125-132.

Mustafa, M. N., \& Zulhafizh. (2018). The use of Technology to Ensure the Quality of Teaching and Learning: Senior High School Teachers' Perspective. In Proceedings of the UR International Conference on Educational Sciences, 765-771.

Mustafa, M. N., \& Zulhafizh. (2019). Information Mastery By Teachers as A Strategy to Succeed in the Implementation of Teaching and Learning Activities. In International Seminar and Annual Meeting BKS-PTN Wilayah Barat, 1(1), 516-523.

Mustafa, M. N., \& Zulhafizh. (2017). Building the Professionalism of Teachers as an Effort to Improve Education. In Husein, R, et al (Eds.), International Seminar and Annual Meeting 2017 Fields of Linguistics, Literature, Arts, and Culture, Medan, 449.

Mustafa, M. N., Hermandra, \& Zulhafizh. (2020). Pengelolaan Kelas: Upaya Meningkatkan Kualitas Pembelajaran. Yogyakarta: Mirra Buana Media.

Mustafa, M. N., Hermandra, \& Zulhafizh. (2019). Teachers' Strategies to Design Media to Implement Communicative Leaning in Public Schools. Journal of Educational Sciences, 3(1), 13-24.

Mustafa, M. N., Hermandra, Suarman, \& Zulhafizh. (2019). Manajerial Pembelajaran Kreatif: Menjadi Guru Jitu. Yogyakarta: Mirra Buana Media.

Nassaji, H. (2012). The Relationship Between SLA Research and Language Pedagogy: Teachers' Perspectives. Language Teaching Research, 16(3), 337-365.

Nissa, I. (2018). Mengukur Pengetahuan Konten Pedagogik Guru Matematika: Suatu Kajian Literatur. Jurnal Kependidikan: Jurnal Hasil Penelitian dan Kajian Kepustakaan di Bidang Pendidikan, Pengajaran dan Pembelajaran, 4(1), 60-72. doi:https://doi.org/10.33394/jk.v4i1.902

Provasnik, S., \& Dorfman, S. (2005). Mobility in the Teacher Workforce (NCES 2005-114). Washington, DC: U.S. Department of Education, National Center for Education Statistics. http://nces.ed.gov/pubs2005/2005114.pdf

Reagle, C. (2006). Creating Effective Schools where All Students Can Learn. The Rural Educator, 27(3), 24-33.

Rubio, C. M. (2009). Efective Teachers-Profesional and Personal Skills. Ensayos: Revista de la Facultad de Educación de Albacete, (24), 35-46.

Rusdin, N. M. (2018). Teachers' Readiness in Implementing $21^{\text {st }}$ Century Learning. International Journal of Academic Research in Business and Social Sciences, 8(4), 1293-1306.

Sammons, P., Lindorff, A. M., Ortega, L., Kington, A., \& Hargreaves, A. (2016). Inspiring Teaching: Learning from Exemplary Practitioners. Journal of Professional Capital and Community, 1(2), 1-20. 
Sarwono, J. (2006). Analisis Data Penelitian Menggunakan SPSS. Yogyakarta: Andi Offset.

Shepherd, D. L. (2013). The Impact of Teacher Subject Knowledge on Learner Performance in South Africa: A Within-pupil Across-subject Approach. In International Workshop on Applied Economics of Education, Cantanzaro, 1-32.

Şişman, M., \& Turan, S. (2004). Education and School Management. Education and School Management Handbook. Ankara, Turkish: Pegem Publishing.

Stronge, J. H., Tucker, P. D. \& Hindman, J. L. (2004). Handbook for Qualities of Effective Teachers. Alexandria, VA, USA: Association for Supervision and Curriculum Development.

Syamsinar, S., \& Jabu, B. (2016). The Problems in Professional Competence of Teachers in Teaching English Subject at Vocational High Schools. ELT Worldwide, 2(2), 95-109.

Tanoto Foundation. (2019). Catatanku Pada Akhir Sesi Pelatihan di Bumi Lancang Kuning. https://www.pintar.tanotofoundation.org/catatanku-pada-akhir-sesi-pelatihan-di-bumilancang-kuning/

Undang-Undang Nomor 14 Tahun 2005 tentang Guru dan Dosen

Yew, O. F., \& Jambulingam, M. (2015). Critical Success Factors of E-learning Implementation at Educational Institutions. J. Interdiscip. Res. Educ., 5(1), 17-24.

Zulhafizh, \& Permatasari, S. (2020). Developing quality of learning in the pandemic covid-19 through creative and critical thinking attitudes. Jurnal PAJAR (Pendidikan dan Pengajaran), 4(5), 937-949.

Zulhafizh. (2020). Orientation on Implementation of Learning Curriculum at Senior High School: Teacher's Perspective. Jurnal PAJAR (Pendidikan dan Pengajaran), 4(2), 303-315.

Zulfiati, H. M. (2014). Peran dan Fungsi Guru Sekolah Dasar dalam Memajukan Dunia Pendidikan. Trihayu, 1(1), 1-4. 